\title{
Gene expression and carbonic anhydrase IX promoter methylation in oral cancer and smokers oral mucosa: a pilot study
}

\author{
Mônica Ghislaine Oliveira Alves ${ }^{1,2,3}$, Celina Faig Lima Carta ${ }^{1,2}$, Maria-Elena Padín-Iruegas ${ }^{4}$, Mario Pérez-Sayáns ${ }^{5}$, \\ Rafael López-López ${ }^{6}$, Nieves Martínez Lago ${ }^{6}$, José Manuel Suárez-Peñaranda ${ }^{7}$, Jaqueline Scholz Issa ${ }^{8}$, Abel \\ García-García $^{5}$, Janete Dias Almeida ${ }^{1}$
}

${ }^{1}$ Department of Biosciences and Oral Diagnosis, Institute of Science and Technology, São Paulo State University (Unesp), São José dos Campos, São Paulo 12245-000, Brazil.

${ }^{2}$ University Braz Cubas, Mogi das Cruzes 08773-380, Brazil.

${ }^{3}$ Universidade Mogi das Cruzes, Mogi das Cruzes 08780-911, Brazil.

${ }^{4}$ Human Anatomy and Embriology Area, Functional Biology and Health Sciences Department, University of Vigo, 36310 Pontevedra, Spain.

${ }^{5}$ Oral Medicine, Oral Surgery and Implantology Unit, Faculty of Medicine and Dentistry, 15782 Santiago de Compostela, Spain.

${ }^{6}$ Medical Oncology Department, Translational Medical Oncology Group, Hospital Clínico Universitario and Heath Care Research Institute, 15706 Santiago de Compostela, Spain.

${ }^{7}$ Department of Pathology, Forensic Sciences, University Hospital and School of Medicine of Santiago de Compostela, 15706 Santiago de Compostela, Spain ${ }^{8}$ Smoking Cessation Program, Area of Cardiology, Heart Institute, University of São Paulo School of Medicine Hospital das Clínicas, São Paulo 05403-900, Brazil.

Correspondence to: Dr. Mônica Ghislaine Oliveira Alves, Department of Biosciences and Oral Diagnosis, Institute of Science and Technology, São Paulo State University (Unesp), 777 Eng. Francisco José Longo Avenue, São Dimas, São José dos Campos, São Paulo 12245-000, Brazil.

E-mail: mgoliveiraalves@gmail.com

How to cite this article: Oliveira Alves MG, Lima Carta CF, Padín-Iruegas ME, Pérez-Sayáns M, López-López R, Lago NM, Suárez-Peñaranda JM, Issa JS, García-García A, Almeida JD. Gene expression and carbonic anhydrase IX promoter methylation in oral cancer and smokers oral mucosa: a pilot study. Stomatological Dis Sci 2017;1:109-15.

Article history:

Received: 25 May 2017

First Decision: 10 Oct 2017

Revised: 23 Oct 2017

Accepted: 21 Nov 2017

Published: 25 Dec 2017

Key words:

Carcinoma,

squamous cell,

methylation,

carbonic anhydrase IX,

gene expression,

tobacco
ABSTRACT

Aim: To evaluate the methylation of carbonic anhydrase IX $(C A I X)$ promoter and CAIX gene expression in oral cancer and smokers. Methods: The collected oral cells samples were classified in to five groups, with each group containing 15 samples. Group 1, oral squamous cell carcinoma (OSCC); group 2, normal contralateral mucosa (NCM) of patients from group OSCC; group 3, normal mucosa in chronic smokers (CS); group 4, normal mucosa in ex-smokers (ES) in cessation for one year; and group 5, normal mucosa in never-smokers (NS). Samples were evaluated through methylation-specific polymerase chain reaction (PCR) and quantitative PCR. Results: The CAIX gene was methylated in only $20 \%$ of samples from group OSCC; in groups NCM, CS, ES and NS, all cases were unmethylated. CAIX expression of group OSCC was lower than in NS $(P=0.005)$. There was no statistically significant difference between CAIX expression in other groups, NCM and NS $(P=0.285), \mathrm{CS}$ and NS $(P=0.530)$ and $\mathrm{ES}$ and NS $(P=0.068)$. Conclusion: CAIX methylation is higher in oral cancer and its expression is reduced in the same cases whose methylation is present. However, the methylation profile and the expression of this gene are not modified in chronic smokers and ex-smokers after one year of smoke cessation.

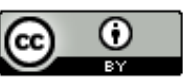

This is an open access article licensed under the terms of Creative Commons Attribution 4.0 International License (https://creativecommons.org/licenses/by/4.0/), which permits unrestricted use, distribution, and reproduction in any medium, as long as the original author is credited and the new creations are licensed under the identical terms.

For reprints contact: service@oaepublish.com

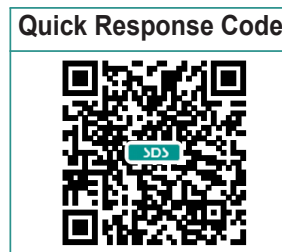




\section{INTRODUCTION}

Oral carcinogenesis is a multifactorial process with several stages, involving numerous genetic and epigenetic changes. It is modulated by hereditary predispositions and environmental influences ${ }^{[1]}$. Abnormalities of these processes can give rise to a phenotype with increased cell proliferation and loss of cellular cohesion, causing local infiltration and metastasis $^{[2]}$.

The squamous cell carcinoma (SCC) is the most common oral malignancy. It is more common in men and the tongue is the most frequent location ${ }^{[3]}$. The diagnosis of oral SCC (OSCC) is based on clinical and histopathological findings. However, the analysis of exfoliative cytology can detect early-stage lesions, reducing morbidity and mortality ${ }^{[4]}$. This analysis is a noninvasive, painless, convenient and low-cost complementary test ${ }^{[5]}$, which can provide information about epithelial cells ${ }^{[6]}$.

The process of carcinogenesis is accompanied by metabolic disorders, such as hypoxia and acidification of the extracellular medium ${ }^{[7,8]}$. Carbonic anhydrase (CA) are transmembrane zinc metalloenzymes which catalyze the reversible hydration of carbon dioxide into carbonic acid, thereby regulating the $\mathrm{Ph}^{[0]}$. PérezSayáns et al. ${ }^{[10]}$ in 2012 concluded that CAIX was overexpressed in tumor cells and advanced stage tumors, these expression levels were statistically significantly higher than initial stage tumors. The authors emphasized the significant improvement in the survival of patients with moderate or negative CAIX expression in contrast to those with intense CAIX expression. Therefore, it appears to be a good prognostic marker for OSCC ${ }^{[10]}$. Choi et al. ${ }^{[11]}$ in 2008 and Brockton et al. ${ }^{[12]}$ in 2011 agreed that the higher expression might be associated with less favorable prognosis.

There are previous studies of $C A I X$ expression in oral cancer $^{[10,11,13]}$ and epithelial dysplasia ${ }^{[14]}$. To the best of our knowledge, there are no studies linking tobacco use to CAIX expression. And there are no studies that assess the methylation of CAIX promoter in OSCC. Thus, this study aimed to evaluate the CAIX promoter methylation and $C A I X$ expression in oral cancer and chronically exposed oral mucosa to tobacco using exfoliative cytological samples.

\section{METHODS}

\section{Patients and samples}

This study was a multicenter study, and it was approved by the research ethics committee of Galicia, Spain and by the São Paulo State University (Unesp), Institute of Science and Technology. Informed consent was obtained from each participant.

Each group was composed of 15 samples of oral smears from males, with the diagnosis of OSCC. OSCC is more common in men than in women. In the OSCC's group, all patients were chronic smokers' men, consuming, at least, 20 cigarettes/day and had drinking habits; the alcohol consumption was frequent and weekly. Group 2 equivalent normal contralateral mucosa (NCM) in patients from group OSCC; group 3, chronic smokers (CS) with consumption of at least ten packs of cigarettes/year; group 4 by 15 ex-smokers (ES) in cessation for one year and group 5 by neversmokers (NS). These samples were collected at the Oral Medicine, Oral Surgery, and Implantology Unit of the Faculty of Medicine and Dentistry, University, of Santiago de Compostela; at the Smoking Cessation Program of Heart Institute, University of São Paulo School and at the outpatient clinic of Oral Medicine of São Paulo State University (Unesp), Institute of Science and Technology. The exfoliative cytology from groups CS, ES and NE were performed in the oral mucosa with no visible clinical changes in equivalent locations of the lesions of group OSCC.

Inclusion criteria for CS, ES and NS groups were: (1) male individuals with no history of oral malignancy and (2) no visible clinical signs of any change at the evaluated location and less than $20 \mathrm{~g}$ of alcohol consumption per week ${ }^{[15]}$. Individuals with chronic diseases were excluded from the sample.

The following information was collected in group OSCC: age, gender, tumor site and tumor stage (according to the edition of the American Joint Committee on Cancer's, Cancer Staging Manual) ${ }^{[16]}$.

Additionally, these groups were formed by individuals with gender and age ( \pm three years) equivalent to individuals in group OSCC. Smears were collected from the same site of the lesion in cases from group OSCC. All patients were submitted to extraoral and intraoral clinical examination.

\section{Exfoliative cytology}

Smears were made using Orcellex Rovers Brush ${ }^{\circledR}$ (Rovers Medical Devices, NL, Holland), without previous use of mouthwashes ${ }^{[17]}$. The samples were transported in DNase, RNase and pyrogenic free tubes, protected from light, containing $2 \mathrm{~mL}$ of RPMI (Microvet, Madrid, Spain) and stored at $2-10{ }^{\circ} \mathrm{C}$, also protected from light ${ }^{[6]}$. 
Table 1: Primers information

\begin{tabular}{|c|c|c|}
\hline & & Primers sequences \\
\hline \multirow{4}{*}{ qRT-PCR } & \multirow{2}{*}{ CAIX } & Forward 5'-GCCCAGCACTTTATGATGGT-3' \\
\hline & & Reverse 5'-TACAGGGCTTTGGAGCAACT-3' \\
\hline & \multirow{2}{*}{ GAPDH } & Forward 5'-AGGTCATCCATGACAACTTTG-3' \\
\hline & & Reverse 5'-TTCAGCTCAGGGATGACCTT-3' \\
\hline \multirow{4}{*}{ MSP-PCR } & \multirow{4}{*}{ CAIX } & Methylate forward 5’AGTGTAATGGCGCGATTTC \\
\hline & & Methylate reverse 5'AACGAAACCCCGTCTCTACTAA \\
\hline & & Unmethylate forward 5’TGGAGTGTAATGGTGTGATTTT \\
\hline & & Unmethylate reverse 5'AACAAAACCCCATCTCTACTAAAAA \\
\hline
\end{tabular}

qRT-PCR: quantitative real time polymerase chain reaction; MSP-PCR: methylation specific polymerase chain reaction; CAIX: carbonic anhydrase IX; GAPDH: glyceraldehyde-3-phosphate dehydrogenase

\section{Methylation-specific polymerase chain reaction}

DNA extraction was performed by Trizol technique, and bisulfite conversion was made using EpiTect Bisulfite Kit, according to manufacturer's information (Qiagen, Valencia, Spain).

Methylation-specific polymerase chain reaction (MSPPCR) was used, under the following conditions: $30 \mathrm{~s}$ at $94{ }^{\circ} \mathrm{C}, 1 \mathrm{~min}$ at $53{ }^{\circ} \mathrm{C}, 1 \mathrm{~min}$ at $72{ }^{\circ} \mathrm{C}$ for 35 cycles, $7 \mathrm{~min}$ at $72{ }^{\circ} \mathrm{C}$. The amplification products are run on $2 \%$ agarose gel staining solution, with $5 \mathrm{mg} / \mathrm{mL}$ of REALSAFE nucleic acid staining Solution (Real, Valencia, Spain) and then visualized under ultraviolet light and photographed with a digital camera. In vitro methylated DNA was the positive control for methylated sequences, water was used as a negative PCR control, and DNA from tonsils was used as a control for the unmethylated reaction.

\section{Real-time reverse transcriptase reaction}

Samples were processed at the Molecular Biology Laboratory, University Hospital and School of Medicine of Santiago de Compostela Compostela, Spain. RNA extraction was performed by Trizol technique.

One microliter of RNA was used to measure the absorbance at 260 (A260) and 280 (A280) $\mathrm{nm}$ in a NanoDrop 1000 Spectrophotometer for each sample (Thermo Scientific, Wilmington, Delaware). The estimated concentration of RNA was obtained by multiplying by 40 the value of A260 (ng/mL). The purity, which indicates the quality of RNA, was assessed by the A260/A280 and A260/A230 ratios, where A260/A280 ratio values between 1.8 and 2.0 and A260/A230 ratio values close to 1.7 suggest RNA free of contamination. Integrity was checked by electrophoresis, performed through $1 \%$ agarose gel. Only samples with intact RNA were used. Total RNA was used for reverse transcription with MuLV reverse transcriptase PCR buffer and RNase inhibitor random hexamers (Applied Biosystems, Foster City, USA). This association was incubated at $42{ }^{\circ} \mathrm{C}$ for $45 \mathrm{~min}$, then for transcriptase denaturation at $95^{\circ} \mathrm{C}$ for $5 \mathrm{~min}$, and after at $10^{\circ} \mathrm{C}$. The cDNA was stored at $-80^{\circ} \mathrm{C}$.

The primer sequences were confirmed in the NCBI/ Gene Bank website, which was specific for the species Homo sapiens, and homology. The selected reference gene was glyceraldehyde-3-phosphate dehydrogenase (GAPDH), among other reference genes $^{[18]}$. Primers information is described in Table 1.

The quantitative real-time polymerase chain reaction (qRT-PCR) was carried out in 96-well plates (Applied Biosystems, Madrid, Spain) in an Applied Biosystems 7500 Real-Time PCR system (Applied Biosystems, Madrid, Spain), with a final volume of $20 \mu \mathrm{L}$. These tests were carried out with triplicates. As a negative control, all reagents were added to the last wells of the plates, except for cDNA, and the wells were sealed with optical adhesive (InvitrogenTM, Carlsbad, CA, USA). Thermal cycling conditions were: $95^{\circ} \mathrm{C}$ for $10 \mathrm{~min}$, followed by 40 cycles of $95{ }^{\circ} \mathrm{C}$ for $15 \mathrm{~s}$ and $60^{\circ} \mathrm{C}$ for $60 \mathrm{~s}$. A dissociation curve analysis was added after the final PCR cycle to evaluate the presence of nonspecific PCR products and primer dimers. During initial optimization runs, 10 -fold serial dilutions were employed to demonstrate a linear amplification range for each gene-specific primers.

The relative levels of gene expression were determined using the method of a quantitative curve. Normalization of quantitative cDNA in each sample was performed using the expression of the GAPDH gene as a reference gene.

\section{Statistical analysis}

The statistical analysis of the data obtained by qRTPCR was performed using GraphPad Prism software 5.03 and SPSS 20.0. Data were presented as median, mean and standard deviation. Significance between two groups was determined by Student's $t$ test. A level of significance of $5 \%$ was adopted. 
Table 2: Results of the methylation of carbonic anhydrase IX analysis in all cases

\begin{tabular}{|c|c|c|c|c|c|c|c|c|c|c|c|c|c|c|}
\hline \multicolumn{3}{|c|}{$\begin{array}{l}\text { Oral cell squamous } \\
\text { carcinoma }\end{array}$} & \multicolumn{3}{|c|}{$\begin{array}{c}\text { Normal contraleral } \\
\text { mucosa }\end{array}$} & \multicolumn{3}{|c|}{ Smokers } & \multicolumn{3}{|c|}{ Ex-smokers } & \multicolumn{3}{|c|}{ No smokers } \\
\hline Cases & $M / U$ & $2^{\wedge}-\mathrm{ddCT}$ & Cases & $M / U$ & $2^{\wedge}-d d C T$ & Cases & $M / U$ & $2^{\wedge}-\mathrm{ddCT}$ & Cases & $M / U$ & $2^{\wedge}-d d C T$ & Cases & $M / U$ & $2^{\wedge}-d d C T$ \\
\hline Case 1 & $M$ & 0.006 & Case 1 & U & 0.331 & Case 1 & U & 0.628 & Case 1 & U & 1.101 & Case 1 & U & 1 \\
\hline Case 2 & $U$ & 0.411 & Case 2 & $U$ & 0.872 & Case 2 & $U$ & 0.815 & Case 2 & $U$ & 0.129 & Case 2 & $U$ & 1 \\
\hline Case 3 & $U$ & 0.240 & Case 3 & $U$ & 0.755 & Case 3 & $U$ & 1.259 & Case 3 & $U$ & 1.390 & Case 3 & $U$ & 1 \\
\hline Case 4 & $M$ & 0.007 & Case 4 & $U$ & 0.455 & Case 4 & U & 0.727 & Case 4 & $\mathrm{U}$ & 1.259 & Case 4 & $U$ & 1 \\
\hline Case 5 & $U$ & 0.369 & Case 5 & $U$ & 0.441 & Case 5 & $U$ & 1.014 & Case 5 & $U$ & 0.512 & Case 5 & $U$ & 1 \\
\hline Case 6 & $U$ & 0.344 & Case 6 & $U$ & 0.405 & Case 6 & $U$ & 1.106 & Case 6 & $U$ & 1.419 & Case 6 & $U$ & 1 \\
\hline Case 7 & $M$ & 0.034 & Case 7 & $U$ & 0.475 & Case 7 & $\mathrm{U}$ & 1.224 & Case 7 & $\mathrm{U}$ & 0.455 & Case 7 & $U$ & 1 \\
\hline Case 8 & $U$ & 0.363 & Case 8 & $U$ & 0.702 & Case 8 & $U$ & 0.982 & Case 8 & $U$ & 1.356 & Case 8 & $U$ & 1 \\
\hline Case 9 & $U$ & 0.372 & Case 9 & $U$ & 0.621 & Case 9 & $U$ & 2.562 & Case 9 & $U$ & 0.535 & Case 9 & $U$ & 1 \\
\hline Case 10 & $M$ & 0.055 & Case 10 & $U$ & 0.468 & Case 10 & U & 0.987 & Case 10 & U & 0.492 & Case 10 & $\mathrm{U}$ & 1 \\
\hline Case 11 & $M$ & 0.094 & Case 11 & $U$ & 0.416 & Case 11 & $U$ & 0.691 & Case 11 & $U$ & 1.419 & Case 11 & U & 1 \\
\hline Case 12 & U & 0.440 & Case 12 & $U$ & 0.464 & Case 12 & $U$ & 0.511 & Case 12 & $U$ & 0.109 & Case 12 & $U$ & 1 \\
\hline Case 13 & U & 1.109 & Case 13 & U & 0.841 & Case 13 & $U$ & 0.585 & Case 13 & U & 0.455 & Case 13 & U & 1 \\
\hline Case 14 & $U$ & 1.129 & Case 14 & $U$ & 0.543 & Case 14 & $U$ & 0.664 & Case 14 & $U$ & 1.510 & Case 14 & U & 1 \\
\hline Case 15 & U & 1.257 & Case 15 & $U$ & 0.505 & Case 15 & $U$ & 0.504 & Case 15 & $U$ & 1.390 & Case 15 & $U$ & 1 \\
\hline
\end{tabular}

M: methylated; U: unmethylated

\section{RESULTS}

The average age of group OSCC was $58 \pm 12.65$ years (range 45 to 80 ), all patients in this group had primary OSCC and the most common locations were tongue $(46 \%)$ and the floor of the mouth $(40 \%)$. At diagnosis, $26.66 \%$ of patients had stage I disease, $20 \%$ had stage II disease, $0 \%$ had stage III disease, and $53.33 \%$ had stage IV disease. Well-differentiated cases were $40 \%, 40 \%$ moderately differentiated and poorly differentiated cases were $20 \%$ of the total.

The CAIX gene was methylated in $20 \%$ of group OSCC cases and no case in groups NCM, CS, ES, and NS. The results of the methylation analysis in different cases can be seen in Table 2. There was no statistically significant difference related the methylation status of histological grade $(P=0.43)$, stage $(P=0.11)$ or location of the lesion $(P=0.28)$.

The gene expression can be visualized in Figure 1. There was a statistically significant difference between CAIX expression of group OSCC and group NS patients $(P=0.005)$, with lower expression in group OSCC. There was no statistically significant difference between CAIX expression of the group NCM and NS patients $(P=0.285)$, group CS and group NS patients $(P=0.530)$ and between group ES and NS patients $(P$ $=0.068)$.

\section{DISCUSSION}

CAIX methylation was higher in OSCC and its expression was reduced in the same cases with methylation. However, the profile of gene methylation and expression was not modified in chronic smokers that used tobacco for 20 years or in ex-smokers after one year of smoke cessation. This study aimed to connect methylation CAIX promoter with the low expression of CAIX in oral carcinogenesis process, using exfoliative cytological samples. Therefore, the tumor contralateral normal mucosa was assessed to study the cancerization field, the normal mucosal cells of chronic smokers to study damage caused by chronic use of tobacco, and the normal mucosal cells of ex-smokers after one year of smoke cessation to study the changes in the damage associated to smoke cessation.

CAIX promoter methylation was observed in $20 \%$ of OSCC. No correlation between histological grade, stage or location of the disease was observed. This may be due to a limited number of samples. Studies have demonstrated that CAIX expression is predominantly regulated by methylation of a single CpG site, at the 74 bp position in some kinds of cancers, like renal cancer ${ }^{[19,20]}$ or in diffusetype gastric cancer ${ }^{[21,22]}$. These results suggest the hypoxia-independent regulation of CAIX in this type of cancer ${ }^{[21,22]}$. There are no comparable studies concerning the methylation of CAIX promoter in OSCC. Therefore, it is not possible to compare the preliminary results found. Nevertheless, Beasley et al. ${ }^{[23]}$ (2001) previously suggested that $C A I X$ is regulated by hypoxia in vivo.

In the cases studied in the present research, CAIX methylation was higher in OSCC. Cases with CAIX methylation presented reduced expression of CAIX. 


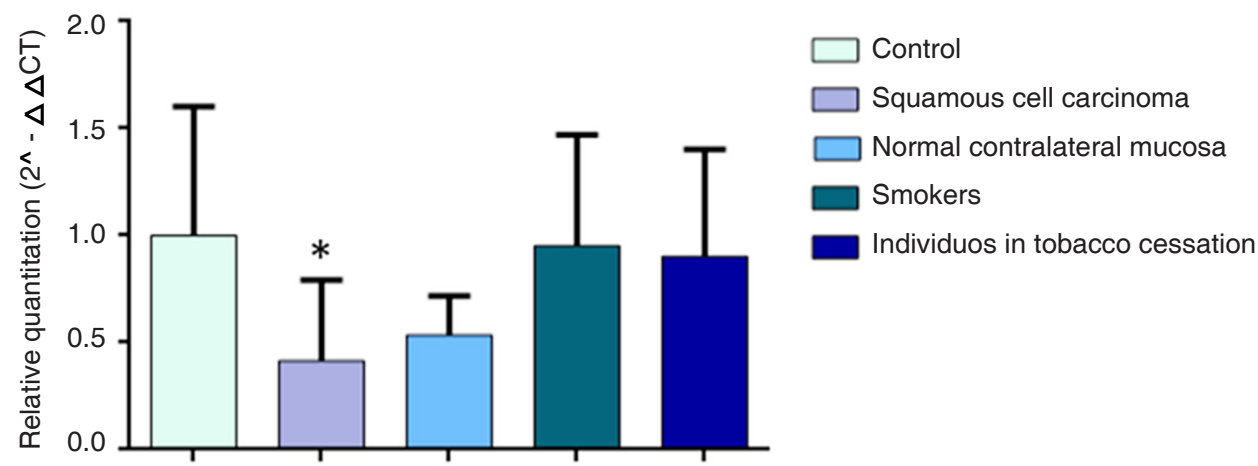

Figure 1: Carbonic anhydrase IX expression, relative quantification (Log) using quantitative real-time polymerase chain reaction. Values are expressed as mean and standard deviation. Student's $t$-test was used to compare gene expression ( $\left.{ }^{\star} P \leq 0.05\right)$

OSCC cases presented lower expression than neversmoker patients' mucosa. To best of our knowledge, no other studies addressing CAIX methylation in OSCC, as well as related to CAIX gene expression in oral mucosa chronically exposed to tobacco. There are many studies evaluating CAIX protein expression in OSCC using different immunohistochemical evaluation methods ${ }^{[10,11,13,24-26]}$. Pérez-Sayáns et al. ${ }^{[10]}$ (2012) concluded that CAIX was overexpressed in OSCC. In contrast, other authors demonstrated protein expression in a limited number of cells $\mathbf{s}^{[11,13,24-26]}$. Kondo et al. ${ }^{[24]}$ (2011) reported that $98 \%$ of OSCC cases showed more than $10 \%$ positive cells in the sample. Kim et al. ${ }^{[13]}(2007)$ found that $63.3 \%$ cases showed more than $10 \%$ positive cells in the sample. Eckert et al. ${ }^{[25]}$ (2012) found CAIX positivity in $42.5 \%$ of OSCC samples. Choi et al. ${ }^{[11]}(2008)$ reported that $58.1 \%$ OSCC cases showed more than $5 \%$ positive cells in the sample. Roh et al. ${ }^{[26]}(2009)$ found $40.47 \%$ OSCC cases with more than $1 \%$ positive cells in the sample.

Additionally, it is important to note that unlike the studies cited, this study used exfoliative cytology, and smears in OSCC were collected in an ulcerated lesion. In other groups, the epithelium was intact.

A lower expression was observed in OSCC if compared to the control. This lower expression may be due to the fact that there are three cases in this group with methylation in CAIX promoter, with lower expression in these cases. As it was observed in the evaluation of methylation, the CAIX profile expression is not modified in tumors in the contralateral normal mucosa, in chronic smokers, and in ex-smokers after a year of smoke cessation. Notably, the exfoliated cells are removed from the surface layers of the epithelium. In this case, it was performed in mucosa without any alteration, as already mentioned. Taking this into consideration, in this study, there was no observed change of the epithelium in the expression of CAIX caused by tobacco use, since CAIX is usually absent in normal epithelium ${ }^{[27]}$.

Pérez-Sayáns et al. ${ }^{[27]}$ (2014) studied epithelial dysplasia adjacent to surgical resection margins of OSCC and found no statistically significant relationship between the expression of CAIX with any other variables, including the degree of dysplasia and the intensity of expression in the tumor. Furthermore, CAIX expression was significantly associated with postoperative disease recurrence and with worse overall survival in patients with oral cancer ${ }^{[11]}$. Kim et al..$^{[13]}$ (2007) showed that the correlation of CAIX expression with prognosis might become indirect evidence that hypoxia is a poor prognostic sign. Pérez-Sayáns et al. ${ }^{[10]}$ (2012) concluded that survival in patients with moderate or negative expression improves significantly in contrast to those patients with intense CAIX expression. However, Kondo et al. ${ }^{[24]}$ in 2011 found that CAIX expression had no significant impact on the survival rate of the patients.

Eckert et al. ${ }^{[28]}$ (2010) studied the expression of CAIX and HIF-1a, finding that low expression of CAIX is associated with increased HIF-1 $\alpha$ expression and it was correlated to worse prognosis, but also that a low expression of both CAIX and HIF-1 $\alpha$ was associated with the best prognosis. The authors discussed that there are two possibilities to explain this phenomenon: CAIX plays no important role in progression of OSCC, or this enzyme possesses different roles in $\mathrm{OSCC}^{[25]}$. Additionally, Eriksen et al. ${ }^{[29]}$ (2007) also concluded that there is no correlation between patient or tumor characteristics with $C A I X$ expression and, apparently, no prognostic value of $C A I X$ was demonstrated. Their results indicate that $C A I X$ alone is not a specific marker for head and neck SCC with known modifiable hypoxia $^{[29]}$.

On the other hand, Eckert et al. ${ }^{[28]}$ and Brockton et al. ${ }^{[30]}$ (2012) found that elevated stromal CAIX expression 
is associated with reduced 5-year disease-specific survival in patients with OSCC.

In conclusion, within the limitations of this study, since it is just a pilot study, it was demonstrated that CAIX's methylation is higher in OSCC and its expression is reduced in cases with methylation. Therefore, authors may consider that $C A I X$ promoter methylation appears in more favorable prognosis cases and not in all cases. The methylation and expression's gene profile was not modified in chronic smokers and ex-smokers with one year of smoking cessation. Further studies, with larger samples, are necessary to better determine the CAIX's role in carcinogenesis stages better.

\section{DECLARATIONS}

\section{Acknowledgments}

The authors thank Rovers Medical Devices for donating a Rovers ${ }^{\circledR}$ Orcellex ${ }^{\circledR}$ Brush, and the Pathology Department of the University Hospital and School of Medicine of Santiago de Compostela, Spain, for their collaboration. The authors also acknowledge the efforts of Dr. Jon Wanger in refining the final manuscript.

\section{Authors' contributions}

Conception and design of the study: M.G. Oliveira Alves, C.F. Lima Carta, M.E. Padín-Iruegas, M. PérezSayáns

Acquisition of data: M.G. Oliveira Alves, C.F. Lima Carta, M.E. Padín-Iruegas, N.M. Lago, J.S. Issa, A. García-García

Analysis and interpretation of data: M.G. Oliveira Alves, M.E. Padín-Iruegas, M. Pérez-Sayáns, J.M. Suárez-Peñaranda

Drafting the article: M.G. Oliveira Alves, M.E. PadínIruegas, M. Pérez-Sayáns

Revising it critically for important intellectual content: M.E. Padín-Iruegas, M. Pérez-Sayáns, R. LópezLópez, A. García-García, J.M. Suárez-Peñaranda, J.D. Almeida

Final approval of the version to be submitted: M.G. Oliveira Alves, C.F. Lima Carta, M.E. Padín-Iruegas, M. Pérez-Sayáns, R. López-López, N.M. Lago, J.M. Suárez-Peñaranda, J.S. Issa, A. García-García, J.D. Almeida

\section{Financial support and sponsorship}

The study was supported by the Coordination for the Improvement of Higher Education Personnel (CAPES), grants \#2012/05371-4 and 2013/06251-5, São Paulo Research Foundation (FAPESP).

\section{Conflicts of interest}

The authors report no conflicts of interest. The authors alone are responsible for the content and writing of this paper.

\section{Patient consent}

Informed consent was obtained from each participant.

\section{Ethics approval}

It was approved by the research ethics committee of Galicia, Spain and by the São Paulo State University (Unesp),Institute of Science and Technology.

\section{REFERENCES}

1. Califano J, van der Riet P, Westra W, Nawroz H, Clayman G, Piantadosi S, Corio R, Lee D, Greenberg B, Koch W, Sidransky D. Genetic progression model for head and neck cancer: implications for field cancerization. Cancer Res 1996;56:2488-92.

2. Pérez-Sayáns M, Somoza-Martín JM, Barros-Angueira F, ReboirasLópez MD, Gándara Rey JM, García-García A. Genetic and molecular alterations associated with oral squamous cell cancer (Review). Oncol Rep 2009;22:1277-82.

3. Lambert R, Sauvaget C, de Camargo Cancela M, Sankaranarayanan R. Epidemiology of cancer from the oral cavity and oropharynx. Eur J Gastroenterol Hepatol 2011;23:633-41.

4. Robinson PN, Mickelson AR. Early diagnosis of oral cavity cancers Otolaryngol Clin North Am 2006;39:295-306.

5. Almeida JD, Cabral LAG, Brandao AAH. Exfoliative cytology as a diagnostic method in stomatology. $J$ Dent Res 1994;73:765.

6. Pérez-Sayáns M, Somoza-Martín JM, Barros-Angueira F, ReboirasLópez MD, Gándara-Vila P, Gándara Rey JM, García-García A. Exfoliative cytology for diagnosing oral cancer. Biotech Histochem 2010;85:177-87.

7. Martinez-Zaguilan R, Lynch RM, Martinez GM, Gillies RJ. Vacuolartype $\mathrm{H}(+)$-ATPases are functionally expressed in plasma membranes of human tumor cells. Am J Physiol 1993;265:C1015-29.

8. Cardone RA, Casavola V, Reshkin SJ. The role of disturbed $\mathrm{pH}$ dynamics and the $\mathrm{Na}+\mathrm{H}+$ exchanger in metastasis. Nat Rev Cancer 2005;5:786-95.

9. Opavský R, Pastoreková S, Zelník V, Gibadulinová A, Stanbridge EJ, Závada J, Kettmann R, Pastorek J. Human MN/CA9 gene, a novel member of the carbonic anhydrase family: structure and exon to protein domain relationships. Genomics 1996;33:480-7.

10. Pérez-Sayáns M, Suárez-Peñaranda JM, Pilar GD, Supuran CT, Pastorekova S, Barros-Angueira F, Gándara-Rey JM, García-García A. Expression of CA-IX is associated with advanced stage tumors and poor survival in oral squamous cell carcinoma patients. J Oral Pathol Med 2012;41:667-74.

11. Choi SW, Kim JY, Park JY, Cha IH, Kim J, Lee S. Expression of carbonic anhydrase IX is associated with postoperative recurrence and poor prognosis in surgically treated oral squamous cell carcinoma. Hum Pathol 2008;39:1317-22.

12. Brockton N, Dort J, Lau H, Hao D, Brar S, Klimowicz A, Petrillo S, Diaz R, Doll C, Magliocco A. High stromal carbonic anhydrase IX expression is associated with decreased survival in P16-negative head-and-neck tumors. Int J Radiat Oncol Biol Phys 2011;80:249-57.

13. Kim SJ, Shin HJ, Jung KY, Baek SK, Shin BK, Choi J, Kim BS, Shin SW, Kim YH, Kim JS, Oosterwijk E. Prognostic value of carbonic anhydrase IX and Ki-67 expression in squamous cell carcinoma of the tongue. Jpn J Clin Oncol 2007;37:812-9.

14. Pastoreková S, Parkkila S, Parkkila AK, Opavský R, Zelník V, Saarnio J, Pastorek J. Carbonic anhydrase IX, MN/CA IX: analysis of 
stomach complementary DNA sequence and expression in human and rat alimentary tracts. Gastroenterology 1997;112:398-408.

15. Lima CF, Oliveira LU, Cabral LA, Brandão AA, Salgado MA, Almeida JD. Cytogenetic damage of oral mucosa by consumption of alcohol, tobacco and illicit drugs. J Oral Pathol Med 2010;39:441-6.

16. Edge SB, Compton CC. The American Joint Committee on Cancer: the 7th edition of the AJCC cancer staging manual and the future of TNM. Ann Surg Oncol 2010;17:1471-4.

17. Fontes PC, Corrêa GH, Issa JS, Brandão AA, Almeida JD. Comparison of exfoliative pap stain and AgNOR counts of the tongue in smokers and nonsmokers. Head Neck Pathol 2008;2:157-62.

18. Rentoft M, Hultin S, Coates PJ, Laurell G, Nylander K. Tubulin $\alpha-6$ chain is a stably expressed reference gene in archival samples of normal oral tissue and oral squamous cell carcinoma. Exp Ther Med 2010;1:419-23.

19. Cho M, Uemura H, Kim SC, Kawada Y, Yoshida K, Hirao Y, Konishi N, Saga S, Yoshikawa K. Hypomethylation of the MN/CA9 promoter and upregulated MN/CA9 expression in human renal cell carcinoma. Br J Cancer 2001;85:563-7.

20. Jakubicková L, Biesová Z, Pastoreková S, Kettmann R, Pastorek J. Methylation of the CA9 promoter can modulate expression of the tumor-associated carbonic anhydrase IX in dense carcinoma cell lines. Int J Oncol 2005;26:1121-7.

21. Chen J, Röcken C, Hoffmann J, Krüger S, Lendeckel U, Rocco A, Pastorekova S, Malfertheiner P, Ebert MP. Expression of carbonic anhydrase 9 at the invasion front of gastric cancers. Gut 2005;54:920-7.

22. Nakamura J, Kitajima Y, Kai K, Hashiguchi K, Hiraki M, Noshiro $\mathrm{H}$, Miyazaki K. Expression of hypoxic marker CA IX is regulated by site-specific DNA methylation and is associated with the histology of gastric cancer. Am J Pathol 2011;178:515-24.

23. Beasley NJ, Wykoff CC, Watson PH, Leek R, Turley H, Gatter K, Pastorek J, Cox GJ, Ratcliffe P, Harris AL. Carbonic anhydrase IX, an endogenous hypoxia marker, expression in head and neck squamous cell carcinoma and its relationship to hypoxia, necrosis, and microvessel density. Cancer Res 2001;61:5262-7.

24. Kondo Y, Yoshikawa K, Omura Y, Shinohara A, Kazaoka Y, Sano J, Mizuno Y, Yokoi T, Yamada S. Clinicopathological significance of carbonic anhydrase 9, glucose transporter-1, Ki-67 and p53 expression in oral squamous cell carcinoma. Oncol Rep 2011;25:1227-33.

25. Eckert AW, Kappler M, Schubert J, Taubert H. Correlation of expression of hypoxia-related proteins with prognosis in oral squamous cell carcinoma patients. Oral Maxillofac Surg 2012;16:189-96.

26. Roh JL, Cho KJ, Kwon GY, Ryu CH, Chang HW, Choi SH, Nam SY, Kim SY. The prognostic value of hypoxia markers in T2-staged oral tongue cancer. Oral Oncol 2009;45:63-8.

27. Pérez-Sayáns M, Suárez-Peñaranda JM, Torres-López M, Supuran CT, Gándara-Vila P, Gayoso-Diz P, Barros-Angueira F, BlancoCarrión A, Gándara-Rey JM, García-García A. Expression of CA IX in dysplasia adjacent to surgical resection margins of oral squamous cell carcinoma. Biotech Histochem 2014;89:91-7.

28. Eckert AW, Lautner MH, Schütze A, Bolte K, Bache M, Kappler M, Schubert J, Taubert H, Bilkenroth U. Co-expression of Hiflalpha and CAIX is associated with poor prognosis in oral squamous cell carcinoma patients. J Oral Pathol Med 2010;39:313-7.

29. Eriksen JG, Overgaard J; Danish Head and Neck Cancer Study Group (DAHANCA). Lack of prognostic and predictive value of CA IX in radiotherapy of squamous cell carcinoma of the head and neck with known modifiable hypoxia: an evaluation of the DAHANCA 5 study. Radiother Oncol 2007;83:383-8.

30. Brockton NT, Klimowicz AC, Bose P, Petrillo SK, Konno M, Rudmik L, Dean M, Nakoneshny SC, Matthews TW, Chandarana S, Lau HY, Magliocco AM, Dort JC. High stromal carbonic anhydrase IX expression is associated with nodal metastasis and decreased survival in patients with surgically-treated oral cavity squamous cell carcinoma. Oral Oncol 2012;48:615-22. 